\title{
EN BUSCA DE LA INFANCIA PERDIDA
}

Sobre Osvaldo Aguirre. Como si fuera hoy. Rosario: El Ombú Bonsai, 2014, 94 pp.

María Julia Rossi

CUNY, John Jay College

Una mansión embrujada es la primera imagen del mundo: así comienza, tras un sueño, el relato de infancia Como si fuera boy, de Osvaldo Aguirre. La narración recupera la fantasía infantil en sus propios términos y así convive con la voz adulta del narrador de los recuerdos, omnipresente. Con excepción de los pocos momentos en los que la voz adulta cede a la sobreinterpretación de las anécdotas infantiles, la frescura de las primeras impresiones llega a los lectores casi intacta. El título -que el narrador invoca como un eco del de las memorias de su madre, una maestra rural devenida en escritora tardía- encierra esa imposible voluntad de que los recuerdos pasados habiten la vida cotidiana de hoy, como si esos días fueran hoy, como si el que uno era en esos días pudiese ser el que uno es ahora, cuando escribe.

El ensayo de geografía urbana del recuerdo que da forma al libro, organizado a través de sus calles numeradas, es esencialmente una descripción poblada de pequeños relatos. La precisa disposición espacial del recuerdo es una excusa para recomponer, como en una maqueta escolar, el barrio de la infancia: la propia casa, la veterinaria del padre, los negocios, el club, el zoológico, el museo, los nombres de las calles, la gomería, la bicicletería, el inquilinato, la tintorería, el cine, la 
terminal. Como si fuera boy es al mismo tiempo un inventario de escenas iniciáticas que tienen lugar en ese escenario del recuerdo: el primer beso en el zoológico; los primeros escarceos con la escritura, a través de imitaciones de las lecturas disponibles; la primera entrevista; la primera comunión; la primera muerte cercana; los primeros encuentros con una lengua extranjera en la parte trasera de una heladería, signados por el fraude de entrecasa; la primera vez que anduvo a caballo y la primera que manejó un auto; la primera lección de natación que le dio el mecánico. En este regocijo de la historia mínima, la Historia Nacional no hace más que un par de tímidas incursiones intrascendentes -la muerte de Perón que coincide, a lo lejos, con la muerte del padre de un compañero de la escuela, mucho más real; la inflación reflejada en la precariedad de los carteles de los precios en la veterinaria del padre, escritos en lápiz-, tal como suelen entrar en las impresiones de un niño, visibles en la medida en que alteran el mundo inmediato.

En los detalles que el narrador rescata hay una composición de lugar determinada (también de tiempo, pero sobre todo de lugar, siendo espacial antes que temporal, como es, el recuerdo). Podemos los lectores encontrarnos en ese ambiente que rodea al niño que aún vive y siempre vivirá en esos recuerdos, en ese primer beso en el zoológico y en sus otras iniciaciones. Pero lo que este libro despierta es el deseo de recordar y la voluntad de retener esos recuerdos singularísimos que hacen a cada uno ser lo que es y lo que fue. Nada extraordinario parece haber ocurrido en la infancia evocada en el libro: esa cotidianeidad de pueblo está habitada por minucias cotidianas seguidas de otras y éstas de otras y así sucesivamente hasta dar con la vida de una persona. ¿Qué singulariza entonces estos recuerdos, compuestos de nimiedades? ¿Qué los salva de la intrascendencia, del olvido? Los rescata la 
escritura, la práctica del recuerdo compartido, primero oralmente, luego escrito e impreso, dispuesto a una circulación que trasciende los límites de la intimidad más o menos compartida. La escenografía que monta Aguirre tal vez sea el mayor hallazgo de Como si fuera hoy: un mundo poblado de detalles ínfimos, singulares e irrepetibles, distinguidos allí donde los nombres propios dan color único al relato: el noticiero que hacían en la escuela, que a la tarde leían por "Radio Impacto"; el periódico "El Informe" que hacían con un amigo; La Academia Mayo, donde se enseñaba dactilografía; la veterinaria Belgrano, con su cartel de letras góticas; el mercadito Vero-Car; los perros Cuál y Quédice; las revistas Billiken y Anteojito, Rico Tipo y Patoruzí; los fascículos Fútbol. Historia del profesionalismo, los libros de Salgari y Verne, los volúmenes Ovinotecnia y Bovinotecnia.

Como si fuera hoy narra una gran escena de escritura que coincide con la de recordar y, así, escribir ese desafío al olvido y la infancia recobrada. Varias veces el narrador, ese hombre que sueña y que recuerda, se hace preguntas que no sabe responder. "¿Cómo se llamaba?”; “¿quién vivía en esa casa?”. Sus respuestas a veces son "no sé", "no estoy seguro", e incluso el silencio. De esos detalles que se intuyen y se ignoran también está compuesto el recuerdo de la infancia. La dificultad -e incluso lo infructuoso del intento- es un tema recurrente: "ya no recuerdo"; "es poco lo que recuerdo"; "cuyo nombre olvidé". Los lectores asistimos también a esos momentos epifánicos en los que, ante nuestros ojos, finalmente consigue recordar. La escena en la que el narrador hace este denodado esfuerzo también se ilumina a veces con la buena memoria y la exclamación del regocijo se comparte: "¡Lo acabo de recordar!", y también la escritura infunde memoria: "ahora lo recuerdo, después de volver varias veces sobre este párrafo". La escena de lectura no es ajena a la 
escritura ni al recuerdo, por momentos compartido: "Al leerle este fragmento, mi madre repone un episodio que yo había olvidado".

Osvaldo Aguirre construye una voz narrativa libre de toda nostalgia que se escribe a sí misma -el tercer "Osvaldo Aguirre" de su familia-, en las páginas de Como si fuera boy, recordando al tiempo que escribe. Periodista, narrador, cronista y poeta, en este libro ofrece momentos de una ficción que se deleita en detalles inspirados en realidades cotidianas. El recordar como desafío, los límites que el olvido impone, la voz de aquél que lo ensaya al tiempo que relata el intento y las escenas que resultan de esa combinación se deslizan entre el presente y el pasado, entre el hombre que recuerda las historias y el niño que las protagoniza. El narrador exhibe su ejercicio del recuerdo para los lectores y en ese recordar aparecen detalles inadvertidos en la experiencia originaria. El subtítulo, Ayudamemoria, es tanto aquello que coopera para que la memoria no se pierda y el resultado de ese ejercicio del recuerdo, no siempre victorioso.

En la segunda mitad del libro el narrador investiga su familia, no sólo a través de testimonios ajenos sino particularmente propios, en los vestigios que éstos dejaron en él. El narrador se extravía en los escritos de otros, de la madre, del padre, en papeles encontrados en el tesoro familiar. "Mi historia familiar me resulta extraña", escribe: de ella recupera retazos de recuerdos que espera recomponer con invención; el relato familiar se disuelve en recuerdos que parecen fabulados. Aquí también, los dos tiempos a la vez: el que esos papeles evocan y el momento de dar con ellos. Enigmas y deducciones se suceden dando paso a la voz del que busca, que a veces encuentra y a veces no. La última escena notable del libro es el incendio que la madre y la hermana del narrador acometen para hacer limpieza o, mejor dicho, el momento cuando el 
narrador se encuentra con los restos de la hoguera que arrasó con parte de la memoria que él está todo el libro obstinándose en recuperar: "Llegué tarde, ni siquiera quedaban las cenizas, sólo la huella de una fogata que había sido muy grande y se extendía ahora como un cráter". 